\title{
Exploração de simulações como forma de estimular 0 aprendizado de conceitos da Cinemática Escalar
}

\section{Elys da Silva Mendes elysmendes@hotmail.com (1) do Amapá, Macapá, Amapá, Brasil \\ Márcia Jussara Hepp Rehfeldt mrehfeld@univates.br

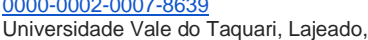 Universidade Vale do Taquar
Rio Grande do Sul, Brasil. \\ Italo Gabriel Neide 0000-0003-0343-7294 \\ talo.neide@univates.br Universidade Vale do Taquari, Lajeado, Rio Grande do Sul, Brasil.}

\begin{abstract}
RESUMO
O presente artigo tem por objetivo descrever uma prática desenvolvida com alunos do 1 으 ano do Curso Técnico em Informática Integrado ao Ensino Médio - (CTIIEM) do Instituto Federal de Educação, localizado no Município de Laranjal do Jari/Ap. Teve como aporte teórico inserir os conceitos da aprendizagem significativa, proposta por Ausubel (2003), e nos estudos de Araujo (2002), Teodoro (2002), entre outros. A metodologia proposta teve como objetivo estimular os estudantes a aprender ativamente, por meio da mediação do professor, conceitos da Cinemática Escalar. A ferramenta tecnológica utilizada foi o software Modellus. Através desta ferramenta foi possível explorar simulações computacionais, oportunizando aos alunos trabalhar com animações das representações virtuais dos fenômenos Físicos associados à Cinemática Escalar. Os resultados mostraram que a metodologia proporcionou a interação entre os alunos submetidos à intervenção pedagógica, bem como despertou predisposição para aprender. Foi possível observar a satisfação dos estudantes em estar utilizando recursos tecnológicos durante seu aprendizado.
\end{abstract}

PALAVRAS-CHAVE: Aprendizagem significativa. Software Modellus. Cinemática Escalar. 


\section{INTRODUÇÃO}

De acordo com Ramos (2011), a forma como se ensina os conteúdos das disciplinas da Física e da Química tem sido pouco atraente para os alunos, ocasionando o insucesso na compreensão de conceitos da área. Isso se deve ao fato de, muitas vezes, os estudantes compreendem as referidas disciplinas como um conjunto de fórmulas abstratas, 'sem muito significado'. Ainda para o mesmo autor, pesquisas realizadas sobre o ensino de Física no Ensino Médio acerca dos métodos tradicionais apontam as fórmulas como uma das possíveis causas das dificuldades de aprendizado dos estudantes. Fiolhais e Trindade (2003) afirmam que esses métodos de ensino estão desajustados das teorias de aprendizagem, pois não utilizam técnicas de ensino mais recentes.

Experiências empíricas dos autores deste estudo mostram que os professores de Física geralmente utilizam, como ferramentas principais de suas aulas, o livro didático, o quadro, o giz e o pincel, o que torna o ensino maçante e aproxima-o de moldes do método tradicional. Com o uso somente desses instrumentos, faz-se necessário que o aluno seja capaz de imaginar o fenômeno natural objeto de estudo, o que, na prática, dificilmente acontece no cotidiano das aulas.

Diante disso, partimos, neste estudo, da premissa de que o uso das Tecnologias de Comunicação e Informação (TICS) nas escolas pode trazer resultados satisfatórios nos processos de ensino e de aprendizagem da Física. Segundo Araujo (2002), o uso de computador e softwares tem contribuído no desempenho dos alunos, quando comparado apenas ao método de ensino tradicional, favorecendo o professor na sua prática docente.

Esta pesquisa, oriunda de uma dissertação de mestrado profissional, teve o intuito de promover mudanças no ensino da Física, em especial na Cinemática, em uma turma de $1^{\circ}$ ano do Curso Técnico em Informática Integrado ao Ensino Médio (CTIIEM), do Instituto Federal de Educação - Campus Laranjal do Jari (IFAP/JL), usando animações desenvolvidas no software educativo Modellus. Segundo o Instituto de Física da Universidade Federal do Rio Grande do Sul ${ }^{1}$, as animações em mecânica, como é o caso deste estudo, oferecem uma visualização direta do previsto pelo modelo adotado para o fenômeno estudado. Nesse sentido, o Modellus permite montar animações ricas e sem dificuldade. Para inserir animações, basta acionar a faixa configuração e clicar na aba objetos.

Acerca do ensino de Física, Cenne e Teixeira, (2007) mencionam que, normalmente, o professor da disciplina dispõe de um único período de aula, o qual é utilizado para os alunos se deslocarem até laboratório, organizarem o material, colherem os dados e discutirem os resultados. Essa situação está entre os fatores que dificultam a utilização desses espaços nas aulas de Física. Os autores apontam, ainda, que uma alternativa para tentar superar tal dificuldade seria o uso de softwares. Assim, seria possível uma ampliação das condições para uma aprendizagem significativa dos conceitos físicos nas mais diversas áreas.

Há de se destacar que o uso de tecnologias encontra algumas barreiras para a sua implementação. Dentre os obstáculos que devem ser superados antes da

Páginłą̌érial disponível em: <http://www.if.ufrgs.br/computador_ensino_fisica/modellus/modellusl_animacao.htm>. Acesso em: 23 jan. 2016. 
inserção da ferramenta tecnológica no ensino está o despreparo da maioria dos professores para trabalhar com esses recursos.

Diante desse cenário, apresentamos um estudo que avaliou as contribuições do uso de animações computacionais exploradas no ensino da Cinemática, buscando aferir a aprendizagem significativa em conceitos da Física por meio das TICs.

\section{Conceitos da Teoria da Aprendizagem Significativa segundo Ausubel}

Para Moreira (2011), a aprendizagem significativa acontece quando ideias expressas simbolicamente interagem de maneira substantiva e não arbitrária com aquilo que o aprendiz já sabe. Segundo o autor, o termo 'substantiva' se refere a não literal, ou seja, não deve ser considerado ao pé da letra. Já a expressão 'não arbitrária' significa, segundo o mesmo autor, que essa interação não é com qualquer ideia prévia, e sim com conhecimentos prévios (subsunçores) relevantes, presentes na estrutura cognitiva do sujeito que aprende.

De acordo com Moreira (2011, p. 18), subsunçor "é um conhecimento estabelecido na estrutura cognitiva do sujeito que aprende e que permite, por interação, dar significado a outros conhecimentos". O autor destaca ainda que tal conceito pode ser uma concepção, um construto, uma proposição, uma representação ou até mesmo um modelo. Tal perspectiva é corroborada por Moreira, Caballero e Rodríguez (1997, p. 20), que comentam:

\footnotetext{
Novas ideias, conceitos, proposições, podem ser aprendidos significativamente (e retidos) na medida em que outras ideias, conceitos, proposições, especificamente relevantes e inclusivos estejam adequadamente claros e disponíveis na estrutura cognitiva do sujeito e funcionem como pontos de "ancoragem" aos primeiros.
}

Para Ausubel (2003), quando acontece a interação de novos significados com as ideias relevantes presentes na estrutura cognitiva do aprendiz, emergem significados verdadeiros ou psicológicos. Assim, os novos conhecimentos adquirem significados e os conhecimentos prévios se modificam. Portanto, a aquisição de novos significados depende de aspectos estruturais cognitivos que se fazem necessários para a reestruturação da nova informação. Ausubel (2003) define a estrutura cognitiva como um conjunto hierárquico de subsunçores dinâmicos e relacionados.

Dessa forma, no campo da aprendizagem significativa, Ausubel (2003) relaciona as condições para sua ocorrência: 1) a aprendizagem deve ser realizada a partir do que o aluno já sabe (conhecimentos prévios); 2) o material de aprendizagem deve ser potencialmente significativo e deve possuir significado lógico para o aluno; 3) o aprendiz (sujeito) deve contar com subsunçores relevantes e específicos, aos quais possam ser 'ancoradas' novas ideias para dar significado ao novo conhecimento; 4) o sujeito deve apresentar predisposição para aprender.

Experiências empíricas dos autores deste artigo mostram que as tecnologias possibilitam aos alunos predisposição ao aprendizado de forma ativa. Nesse 
ensino. Entendemos, ainda, que o método tradicional de ensino, que se baseia no uso da exposição oral, com aplicação de exercícios e resoluções mecanizadas, no qual os estudantes têm que memorizar fórmulas, mostra-se pouco atraente aos alunos. Os Parâmetros Curriculares Nacionais (BRASIL, 2006) também se posicionam de forma contrária a essa metodologia tradicional de ensinar:

Muitas vezes o ensino de Física inclui a resolução de inúmeros problemas, onde o desafio central para o aluno consiste em identificar qual fórmula deve ser utilizada. Esse tipo de questão, que exige, sobretudo, memorização, perde sentido se desejamos desenvolver outras competências(BRASIL, 2006, p. 38).

Assim, se desejamos que o aluno desenvolva novas competências e habilidades, temos que diversificar e inovar no ensino, já que a escola não pode 'parar no tempo'. O papel do professor continua sendo importante em sala de aula, mas ele não é o único detentor do conhecimento, e sim o mediador do aprendizado dos alunos. Nesse contexto, é necessário trazer o aluno para um ensino ativo, colocando-o também como responsável pelo seu aprendizado, visto que, a participação e a interação com o professor pode trazer resultados satisfatórios.

Uma das possibilidades da participação ativa do aluno na própria aprendizagem é a utilização de software educativo em laboratórios de informática. $\mathrm{O}$ ensino associado às TICs tem se mostrado significativo, conforme apontado por Arantes et al (2010, p. 1):

Os avanços dos computadores pessoais, tanto em hardware como na relação custo/benefício, e softwares independentes de plataforma como o Flash e Java, as simulações interativas já constituem um mecanismo eficiente para apresentar conceitos científicos e contribuir para tornar os professores facilitadores e os alunos autônomos nos processos de ensino e aprendizagem.

Nesse sentido, o programa Modellus, segundo Teodoro (1997), permite a criação de função em ambientes de aprendizagem. Ele é um software educacional de modelagem computacional e tem sido utilizado por professores de Ciências, principalmente para as disciplinas de Física, de Química e de Matemática, e está disponível, gratuitamente, com versões em vários idiomas. "O Modellus é uma ferramenta cognitiva para auxiliar a internalização de conhecimento simbólico, preferencialmente em contexto de atividade de grupo e de classe" (TEODORO, 2002, p. 21).

De acordo Araujo, Veit e Moreiral (2004, p. 181), o Modellus "possui uma interface gráfica intuitiva, o que vem a facilitar a interação dos estudantes", bem como favorecer a criação de modelos em tempo real, propiciando múltiplas representações desses modelos, além de permitir observações de experimentos (conceituais) simultaneamente. Araujo (2002, p. 20) cita alguns pontos importantes em que o Modellus se destaca:

- a construção e a exploração de múltiplas representações de modelos;

- a análise de qualidade dos modelos;

- o reforço do pensamento visual, sem memorização dos aspectos de representação formal, por meio de equações e outros processos formais;

- a abordagem de forma integrada dos fenômenos naturais, ou simplesmente representações formais. 
Antes de avançar na descrição das potencialidades do software Modellus, cabe distinguir alguns conceitos usualmente mencionados no ensino de Física, quais sejam: modelos computacionais, simulações e animações. Segundo Neide e Quartieri (2016), nos modelos computacionais, o aluno pode modificar partes estruturantes do um modelo já estabelecido ou criar situações que representam fenômenos físicos. Segundo os autores anteriormente mencionados, o software Geogebra é um exemplo, pois "é possível construir funções e gráficos representados no plano cartesiano, tendo-se a liberdade de variar seus parâmetros e, automaticamente, observar a mudança do comportamento nas funções construídas" (NEIDE e QUARTIERI, 2016, p. 13).

No que tange à simulação computacional, os autores supracitados mencionam que existem limitações, não sendo permitida a modificação do modelo matemático principal em que a situação foi construída. Um exemplo de simulador é o software $P h E T^{2}$, usado em áreas como Matemática, Física, Química, Biologia, entre outras. Portanto, uma simulação permite uma menor interação do aluno com o modelo que representa determinado fenômeno físico.

Por fim, uma animação, segundo Santo e Silva (2003, p. 1), "se caracteriza por mostrar a evolução temporal de um dado evento, e se presta de maneira exuberante para a exposição de fenômenos que se apresentam intrincados para aqueles alunos que não têm uma percepção visual aguçada ou uma capacidade de abstração sofisticada". Nesse caso, também não é permitido realizar modificações nos parâmetros do modelo físico. Segundo Veit e Teodoro (2002), animações interativas como o que permite o software Modellus consentem ao usuário fazer e refazer representações dos modelos computacionais que representam determinados fenômenos físicos.

À luz da teoria da aprendizagem significativa, podemos entender que as animações poderiam exercer a função de organizadores prévios. Estes, de acordo com Ausubel (2003), preenchem o hiato entre aquilo que o aluno já sabe e deveria saber.

Concordamos com Mendes e Almeida (2012), ao relatarem que, quando os professores utilizam recursos com animações, vídeos e computadores, é notório o envolvimento dos alunos, os quais interagem de maneira mais participativa se comparado com as aulas ministradas de modo tradicional. Ainda segundo os autores, o ensino tradicional faz com que alguns alunos sejam meros espectadores em sala de aula.

A Figura 1 apresenta a tela principal da ferramenta tecnológica usada no estudo.

${ }^{2}$ Disponível em: <https://phet.colorado.edu/pt_BR/>. 
Figura 1 - Interface do programa Modellus com as representações das principais comandos

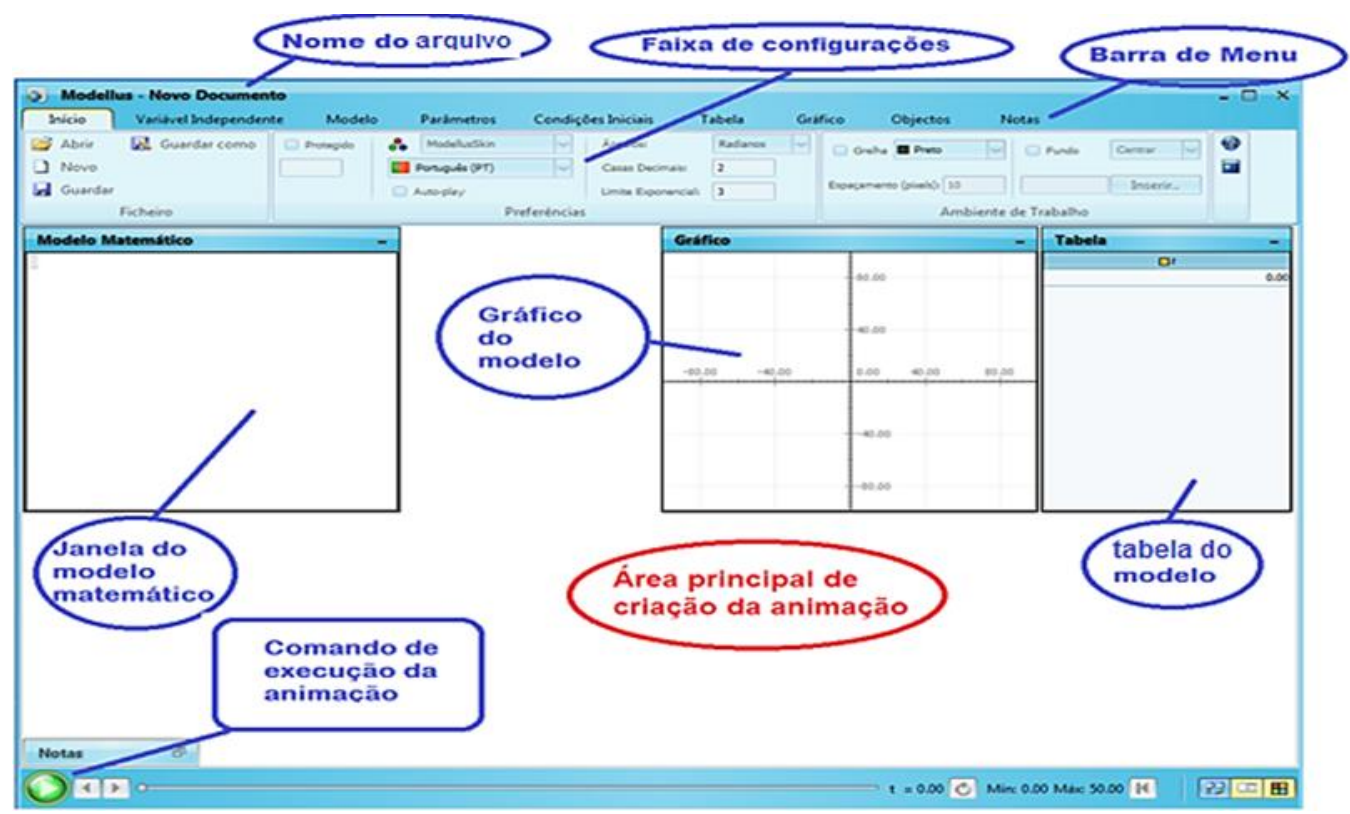

Fonte: Software Modellus versão 4.01. 2014

Para se usar a ferramenta, não é necessário que os ambientes informatizados tenham acesso à rede mundial de computadores. Ramos (2011) destaca algumas das ações que são possíveis de serem realizadas com o Modellus:

- criar e explorar modelos baseados em equações matemáticas (corresponde a retificar conceitos matemáticos, tratando-os como objetos reais);

- visualizar e manipular gráficos e tabelas;

- alterar valores de parâmetros e trabalhar com esses "casos" diferentes;

- gravar os ficheiros para posterior consulta e/ou edição.

Neste estudo, o software Modellus foi utilizado para o ensino da Cinemática de forma interativa, favorecendo ao aluno participar ativamente. Tal recurso favoreceu a interação do aluno com a ferramenta computacional, que se deu a partir da mediação do professor. Teixeira e Veit $(1999$, p. 6) numa versão adaptada de Teodoro, Vieira e Clérigo, mencionam que

uma característica do Modellus é a possibilidade de funcionar como «sistema de autor», isto é, permitir ao professor preparar a representação de um "modelo» complexo que pode ser utilizado por alunos que ainda não disponham dos conhecimentos necessários para compreender a natureza matemática do modelo.

Antes de descrever os resultados obtidos, descreveremos os caminhos metodológicos trilhados. 


\section{Caminhos Metodológicos}

Realizamos o presente estudo em duas etapas, sendo que na primeira, os alunos participaram de aulas expositivas em que foram abordados conceitos de Cinemática Escalar. Já no segundo momento, os estudantes foram levados a explorar, no software Modellus, atividades práticas, propostas e criadas pelos autores deste artigo (Apêndices A e B). Esse momento aconteceu em um dos laboratórios de informática do IFAP/LJ. Cabe ressaltar que as referidas atividades foram embasadas no pré-teste realizado e no perfil dos estudantes, identificado por meio de um questionário previamente aplicado.

Neste artigo, descrevemos apenas duas das atividades, as quais foram realizadas após o pré-teste. Ressalta-se que os professores/pesquisadores elaboraram os modelos matemáticos, cabendo aos alunos realizar as animações.

Metodologicamente, a pesquisa é qualiquantitativa ${ }^{3}$. Eisner (1981) relata que um estudo educacional não tem uma única perspectiva; logo, segundo o autor, a questão não é contratar um estudo qualitativo e não qualitativo, visto que "olhar através de um só olho nunca proporcionou muita profundidade de campo" (EISNER, 1981, p. 9). Já Appolinário (2012, p. 59) afirma que "é muito difícil que haja alguma pesquisa totalmente qualitativa, da mesma forma que é altamente improvável existir alguma pesquisa completamente quantitativa".

A coleta de dados da parte da pesquisa aqui apresentada possibilitou o uso de diferentes instrumentos, tais como um questionário (Apêndice C), observações das atitudes e análise dos documentos criados pelos alunos durante tratamento metodológico do estudo. Todas as observações foram anotadas em um diário de campo. As atividades práticas da pesquisa abordaram conceitos específicos da Cinemática (Tabela 1). Cada atividade prática possui questões para os alunos responderem a partir da interação com a animação.

${ }^{3}$ Aqui será analisada apenas a parte qualitativa da pesquisa. 


\begin{tabular}{|c|c|c|c|c|}
\hline \multicolumn{5}{|c|}{$\begin{array}{l}\text { Atividades práticas de exploração do software realizadas no laboratório de } \\
\text { Informática }\end{array}$} \\
\hline № & $\begin{array}{l}\text { Duração } \\
\text { Média }\end{array}$ & Atividade & Estratégia de ensino & $\begin{array}{l}\text { Conceitos da Cinemática } \\
\text { explorados }\end{array}$ \\
\hline 01 & 3h/aula & $\begin{array}{l}\text { Aula prática de } \\
\text { exploração } \\
\text { animação } \\
\text { Deslocamento em } \\
\text { função da Distância } \\
\text { percorrida. }\end{array}$ & $\begin{array}{l}\text { Aulas mediadas de } \\
\text { introdução à Cinemática } \\
\text { por meio da exploração } \\
\text { do software Modellus. }\end{array}$ & $\begin{array}{l}\text { - Unidades de Medida } \\
\text { - Referencial } \\
\text { - Deslocamento } \\
\text { - Distância percorrida } \\
\text { - Trajetória } \\
\text { - Posição }\end{array}$ \\
\hline 02 & $3 h / a u l a$ & $\begin{array}{l}\text { Aula prática de } \\
\text { exploração da } \\
\text { animação: } \\
\text { Velocidade Escalar } \\
\text { Média e Aceleração } \\
\text { Escalar Média. }\end{array}$ & $\begin{array}{l}\text { Aulas mediadas com } \\
\text { práticas de exploração } \\
\text { do software Modellus } \\
\text { que envolvem os } \\
\text { conceitos de Velocidade } \\
\text { Escalar Média e } \\
\text { Aceleração Escalar. }\end{array}$ & $\begin{array}{l}\text { - Velocidade Média } \\
\text { - Aceleração }\end{array}$ \\
\hline
\end{tabular}

Fonte: Pesquisadores, 2014.

Análise, Resultados e Reflexões

Nesta seção, descrevemos as atividades que tratam dos conceitos da Física no ensino da Cinemática. As atividades tiveram como objetivo mostrar as relações entre os conceitos e, sobretudo, possibilitar aos alunos a compreensão e/ou modificação dos possíveis "erros" conceituais empíricos. As práticas pedagógicas aqui retratadas aconteceram no mês de março de 2014, e tiveram duração de duas semanas, contando com a participação de 19 alunos. Para manter o anonimato dos alunos participantes, utilizamos códigos. Dessa forma, os sujeitos foram identificados pela letra " $A$ " seguido por um número correspondente ao aluno no diário de classe.

Atividade 1 - Deslocamento em função da distância percorrida

Os procedimentos iniciais dessa atividade consistiram em mostrar aos alunos os recursos e potencialidades que o software Modellus disponibiliza. Em seguida os alunos começaram a explorar a atividade proposta.

Ao observarem o desenvolvimento da animação gerada, o aluno A3 perguntou: Professor, foi difícil criar esta simulação nesse programa, pois parece tão difícil fazer? Em resposta, relatamos que a ferramenta é de linguagem simples e que, para criar animações como a que estávamos trabalhando, faz-se necessário, não só conhecimentos básicos de informática e de conceitos do conteúdo da Física tratados, como também criatividade.

Dando prosseguimento à atividade, pedimos aos alunos que começassem a responder às perguntas e, já na primeira questão, notamos a dificuldade da 
maioria. Assim, vimos a oportunidade para começar a discutir os conceitos da Cinemática abordadas na questão. Contudo, ressalta-se que não apresentamos os conceitos de forma direta, mas sim fizemos com que os alunos interagissem com o aplicativo. Nesse sentido, convergimos com os preceitos apresentados por Araujo (2002, p. 12), quando afirma que "o Modellus vem a facilitar a interação dos estudantes com modelos em tempo real e a análise de múltiplas representações". O autor supracitado comenta, ainda, que as representações desses modelos permitem ao aluno observar vários experimentos conceituais simultâneos.

Nessa vertente, considerando que o estudante tem a possibilidade de observar múltiplos conceitos por meio da representação de um modelo, fizemos a seguinte inferência sobre a animação: Deslocamento em função da distância percorrida: Observando a execução da animação, qual é a posição inicial do atleta? As respostas dos alunos A8 e A15 resumem o que a maioria respondeu:

A8: Posição zero, pois não correu nada.

A15: No início o atleta ainda não entrou em movimento, então ele sai da posição zero.

Tendo em vista a incoerência das respostas, pedimos aos alunos que executassem novamente a animação, e que fizessem anotações em seus cadernos, observando as informações presentes na imagem de fundo da animação. Em seguida, refizemos a pergunta anterior: Qual é a posição inicial? O aluno A6 disse: Professor! Entendi que a posição inicial é de 100 metros. Questionamos, então, como ele havia chegado a essa conclusão. Em resposta, ele disse: Olhei a imagem que tinha um valor de 100 metros, então como o atleta está saindo dali, aquela é a posição de início.

Posteriormente, perguntamos: Agora que já observaram a posição inicial do atleta, qual é a sua posição final? O aluno A19 disse: Ele parou seu movimento em 800 metros, então, acho que essa é a posição final. Questionamos à turma se todos estavam de acordo com essa resposta e não houve divergências.

Na sequência, solicitamos que respondessem à primeira questão: Calcule o deslocamento do atleta. Todos os alunos representaram matematicamente o deslocamento do atleta da animação. Na Figura 2, está a representação matemática do deslocamento elaborada pelo aluno A14.

Figura 2 - Representação matemática do deslocamento do aluno A14

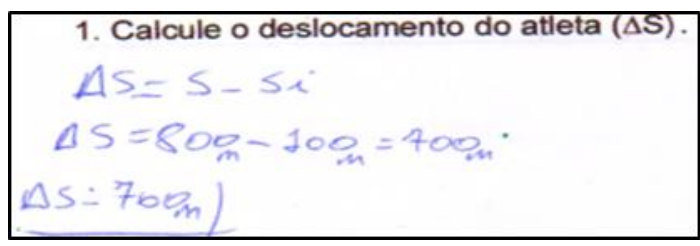

Fonte: Dados da Pesquisa, 2014.

Em seguida, submetemos a turma à pergunta: Agora que vocês já conseguiram representar matematicamente o deslocamento do atleta, definam o conceito de 
A6: No deslocamento é quando o atleta sai de uma posição e vai até outra.

A13: O deslocamento é o resultado da diferença entre a posição inicial e do ponto final.

A19: Deslocamento é o valor da distância que o atleta correu no caminho.

O objetivo da questão era possibilitar que os alunos compreendessem que o deslocamento de um 'corpo' está relacionado à diferença de posição ao longo de uma trajetória. Para isso, considera-se a diferença de posição inicial e final. Dessa forma, para verificar se o objetivo foi alcançado, formulamos a segunda questão: Considere agora que o atleta foi até a posição final [S] e retornou em seguida. Nesse caso, qual foi o deslocamento do atleta? Dos 19 alunos, 17 relataram que o deslocamento do atleta foi zero. De fato, a animação mostra que, se o atleta sai de uma posição e retorna para a mesma posição de origem, não há deslocamento, haja vista, que o deslocamento é a medida da linha reta que une a posição inicial e a posição final. Assim, o seu valor só depende destas posições, e não da trajetória. A Figura 3 mostra a resposta do aluno A3.

Figura 3 - Resposta do aluno A3

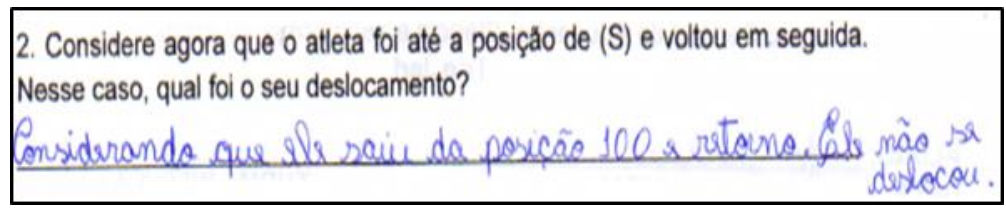

Fonte: Dados da pesquisa, 2014.

$\mathrm{Na}$ continuidade da atividade, eles responderam sem maiores dificuldades a terceira questão. Nessa, os alunos tinham que determinar o intervalo de tempo entre o início e fim do movimento do atleta da animação. Dos 19 alunos, 16 apresentaram a resposta por meio de representações matemáticas, fazendo a diferença entre tempo inicial e final do trajeto do atleta da animação. Três alunos responderam por meios de texto suas repostas, sem a representação matemática, mas que estavam também corretas. A Figura 4 mostra a representação matemática do intervalo de tempo do aluno A7.

Figura 4 - Representação matemática do intervalo de tempo do aluno A7

$$
\begin{aligned}
& \text { 3. Determine o intervalo de tempo entre o inicio e o fim da trajetória. } \\
& \Delta t=t-t_{i} \\
& \Delta t=70-0=70 \text { vegundos. }
\end{aligned}
$$

Fonte: Dados da pesquisa, 2014.

O objetivo dessa questão foi possibilitar aos alunos compreender que "intervalo de tempo" é definido pelas diferenças entre duas medidas temporais instantâneas durante o percurso de um objeto.

Na sequência, na quarta questão, abordamos o conceito de distância percorrida. Para isso, elaboramos a pergunta: Observa-se, na animação, que o atleta sai da posição de início e vai até a posição final. Nessa situação, qual foi à distância que ele percorreu na ida? O aluno A15 disse: "professor ele sai da posição de 100 metros e vai até 800 metros". Então confirmamos: É exatamente isso que 
está representado quando se executa a animação! Mas qual é à distância? O aluno respondeu: Ah! Professor! É a mesma do deslocamento 700 metros. Nesse momento, o aluno A9 disse: Acho que o atleta não percorreu 700 metros. Então intervimos e perguntamos: Por que você acha que a resposta não é 700 metros? Ele respondeu: vejo que, na animação, o atleta sai da posição de 100 metros e chega à posição de 800 metros, então ele correu oitocentos metros. Assim, perguntamos para turma: Quem tem outro resultado para a distância que o atleta percorreu? Nesse instante, nenhum outro aluno se manifestou e pedimos que executassem a animação observando a janela "tabela do modelo". O aluno A15 confirmou sua reposta: Professor! Observo que a distância mostrada na "tabela do modelo" é mesmo 700 metros.

Nesse momento, observamos que eles já apresentavam indícios da aprendizagem do conceito de distância percorrida e solicitamos que respondessem à questão: Calcule a distância percorrida pelo atleta no trajeto de ida e volta. Assim, dos 19 alunos, 13 apresentaram respostas por meio da representação matemática $\left[\mathrm{d}=\Delta \mathrm{S}_{\text {ida }}+\Delta \mathrm{S}_{\text {volta }}\right.$, na qual somaram o deslocamento na ida ao o deslocamento na volta. Os seis restantes optaram por apresentar a resposta por meio de texto. Apresentamos, na Figura 5, a resposta do aluno A11, que respondeu em forma de texto, e a do aluno $A 14$, que respondeu a questão por representação matemática.

Figura 51 - Resposta dos alunos A11 e A14

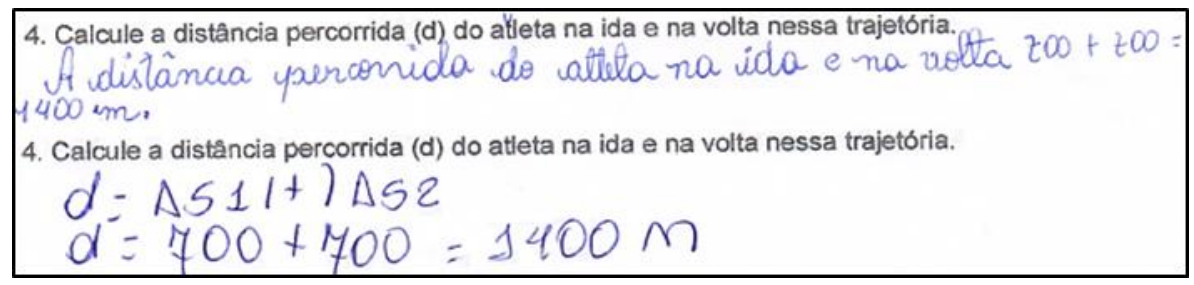

Fonte: Dados da pesquisa, 2014.

Depois de ter abordado os conceitos de deslocamento e distância percorrida, passamos para a quinta questão: De acordo com a animação, qual é a diferença entre deslocamento e distância percorrida? O objetivo foi verificar se houve indícios da aprendizagem significativa em relação a tais conceitos. O intuito dessa pergunta segue uma sugestão de Ausubel (2003) sobre como verificar as evidências de aprendizagem significativa nos estudantes. Segundo o teórico, quando se solicita ao estudante que ele diferencie ideias relacionadas e não idênticas, obtendo uma resposta "genuína de um conceito ou proposição com significados claros, precisos, diferenciados e transferíveis" (MOREIRA; MASINI, 2011, p. 24), evidencia-se a ocorrência da aprendizagem significativa no estudante.

Nesse sentido, dos 19 alunos que participaram dessa atividade, 13 mostraram respostas claras, diferenciadas e transferíveis dos conceitos abordados na atividade (conceitos de deslocamento e distância percorrida), três apresentaram respostas incompletas, e os outros três alunos respostas confusas, necessitando rever conceitos. Moreira e Masini (2002) afirmam que a aprendizagem significativa acontece quando modificações relevantes nos atributos da estrutura cognitiva do aprendiz acontecem pela mediação pedagógica ou através de objetos de aprendizagem potencialmente significativos, que favoreçam a interação do conhecimento existente com o novo conhecimento a ser aprendido. 
Desse modo, foi possível observar evidências de aprendizagem significativa dos conceitos de deslocamento e distância percorrida com treze alunos. Já no restante deles, notamos que o uso das animações reestruturou ou modificou a forma como esses conceitos se apresentavam na sua estrutura cognitiva, o que posssibilitou a aquisição de novos significados a partir dos já aprendidos. Apresentamos, na Figura 6, a resposta do aluno A16.

Figura 6 - Resposta do aluno A16

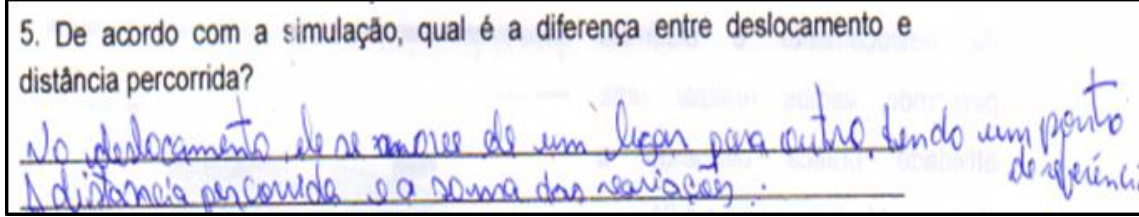

Fonte: Dados da pesquisa, 2014.

Por meio da fala dele, percebemos que essa atividade de animação, ou seja, a imagem do que estava acontecendo, auxiliou o aluno a compreender dos conceitos de deslocamento e de distância percorrida. Respostas como as apresentadas pelos alunos $A 1, A 5$ e $A 6$ evidenciam o quanto um enfoque metodológico diferente no ensino favorece o aprendizado, bem como aguça o interesse deles em aprender.

A1 - A aula no computador foi bem interessante, aprendi sozinho o assunto utilizando a imagem.

A5 - Achei que não ia conseguir acompanhar meus colegas na atividade já que não sei muito de computador, mas no final achei bacana porque pude me aprofundar no estudo da Física a entender as fórmulas.

A6 - A atividade é muito boa e mais prática que na sala que estava um pouco chato lá, e o software é bem legal de estudar com ele.

Dando continuidado ao capítulo que trata das implicações do uso do software Modellus, apresentamos, na sequência, as análises e resultados encontrados na atividade dois. Nesta, abordamos os conceitos de velocidade escalar média e de aceleração escalar.

\section{Atividade 2 - Velocidade escalar média e aceleração escalar}

O objetivo desta atividade foi possibilitar aos alunos o desenvolvimento de habilidades de resolução de problemas, por meio da interação da animação proposta no software Modellus, e, por consequência, que compreendessem os conceitos de velocidade escalar média e aceleração escalar média, por meio da interação com a ferramenta tecnológica.

Inicialmente, a atividade estava prevista para ter duração de 2 horas/aula, mas achou-se conveniente estender o tempo para 3 horas/aula. A proposta foi desenvolvida no mesmo dia, isto é, sem interrupção, devido à necessidade de se aprofundar os conceitos tratados. Dessa forma, igualmente à atividade anterior, pedimos aos alunos a execução da atividade: Modelo 02 - Velocidade escalar média e a aceleração escalar média. Nela, os alunos foram orientados a solucionar as questões propostas na janela nota da ferramenta. Além disso, na área principal do 
software, eles encontraram os parâmetros necessários para interagir com a ferramenta.

Nas duas primeiras horas/aulas, deixamos os alunos livres para explorar a atividade. Nesse momento, observamos as atitudes dos alunos ao interagir com a ferramenta e percebemos que, enquanto a utilizavam, constantemente faziam anotações. Das atitudes observadas, notamos o compartilhamento de informações entre alunos, bem como a ajuda mútua entre eles para solucionar as questões propostas da atividade.

A questão 1 da atividade foi subdividida em quadro itens: no primeiro abordamos os conceitos de deslocamento e trajetória já tratados na atividade 1; no segundo o tempo de trajetória; no terceiro aprofundamos o conteúdo, abordando o conceito de velocidade escalar média; e no quarto item, indagamos os alunos sobre o que acontecia com a velocidade do móvel após a mudança de sentido do movimento. O objetivo desse último item foi introduzir a classificação dos movimentos quanto ao seu sentido, o que seria tratado nas duas questões seguintes.

Dessa forma, solicitamos aos alunos que apresentassem sua resposta. Os resultados mostram que 17 alunos solucionam a questão corretamente e os dois restantes não apresentaram uma justificativa do item quatro. Na Figura 7, mostramos a solução da questão do aluno A16.

Figura 7 - Resposta apresentada do aluno A16

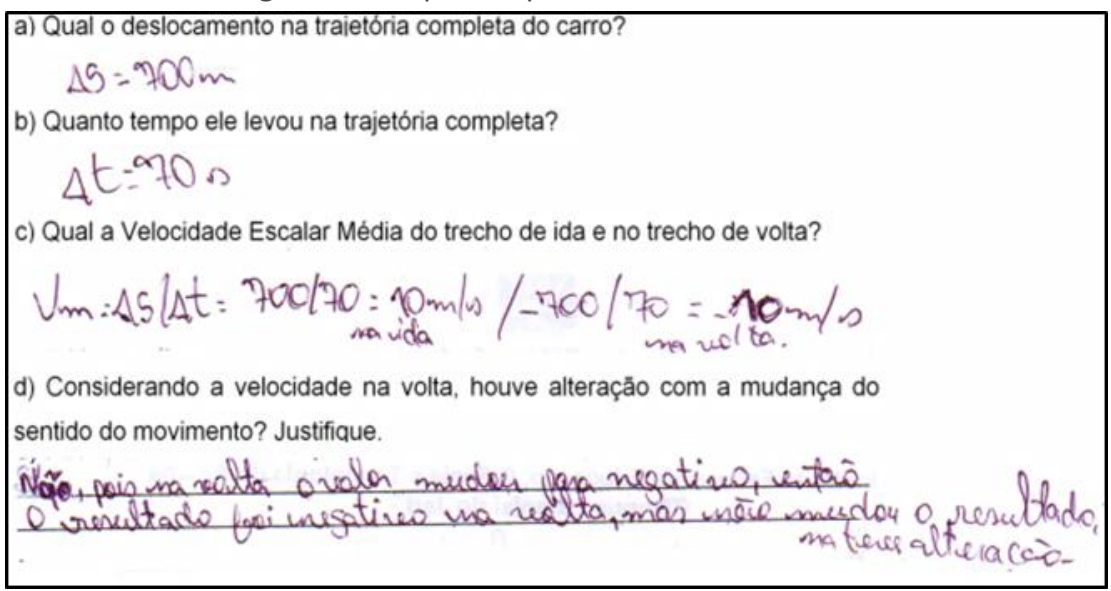

Fonte: Dados da pesquisa, 2014.

Analisando os itens "a" e "b" da questão dessa atividade, pudemos verificar que não houve dificuldade por parte dos alunos. No item "c", 14 alunos conseguiram solucionar pelo simples cálculo de substituição de termos, utilizando a fórmula de velocidade média $[\mathrm{Vm}=\Delta \mathrm{s} / \Delta \mathrm{t}]$ e três apresentaram a resposta na forma de texto.

Para solucionar as questões 2 e 3, os alunos interagiram com a animação. Solicitamos que executassem a animação observando a variável tempo [t] e a posição [s] na ida e na volta do móvel mostrada na janela principal do modelo. Em seguida, pedimos que classificassem o movimento do móvel na ida e na volta quanto ao seu sentido. Os 19 alunos classificaram corretamente o movimento; 
contudo, somente 17 alunos justificaram-no. Vale ressaltar que, na ida, o móvel possui na animação movimento progressivo, pois sua distância aumenta em relação ao referencial, conforme há progressão temporal. Já na volta, o movimento é retrógrado, pois a distância em relação ao referencial diminui com o passar do tempo. Apresentamos, na Figura 8, a resposta do pelo aluno A1.

Figura 8 - Resposta apresentada pelo aluno A1

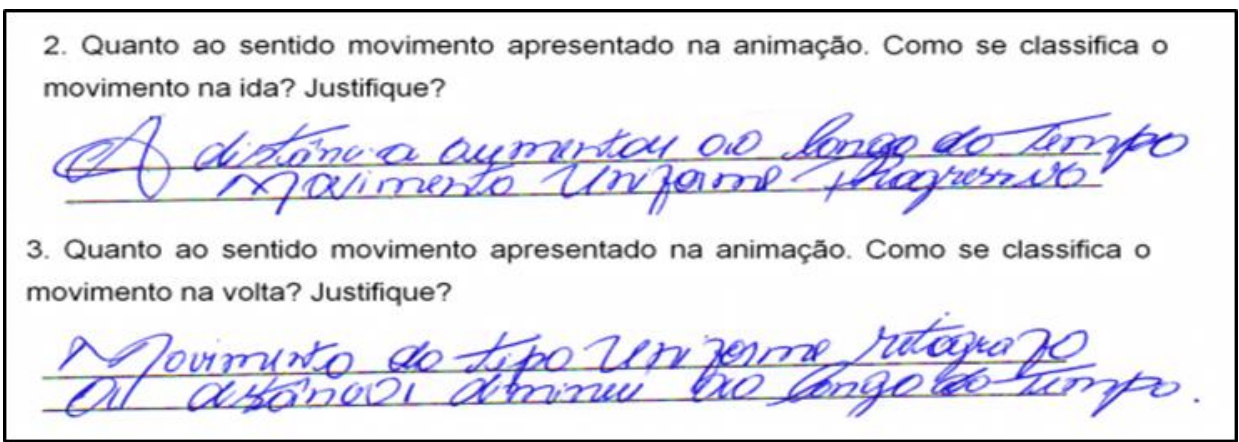

Fonte: Dados da pesquisa, 2014.

Nessas duas questões, consideramos que a situação mostrada na animação possibilitou observar indícios de que os alunos internalizarem os conceitos. Dessa forma, as verbalizações apresentadas nas questões indicam a existência de elementos notórios da compreensão dos significados abordados. Nesse contexto, Moreira (2011) enfatiza que, na teoria da aprendizagem significativa de Ausubel (2003), uma maneira de observar evidências da aprendizagem é quando os alunos são postos em uma situação de aprendizagem, diante da qual mostram a capacidade de verbalizar as ideias. Segundo o teórico, isso acontece quando que os estudantes possuem significados claros, precisos e diferenciados nas suas estruturas cognitivas.

Na questão quatro, os alunos deveriam observar a animação para determinar o tempo de percurso em uma trajetória completa, bem como a distância percorrida pelo móvel, ou seja, indo da posição de referência inicial e retornando para a mesma posição. Nessa questão, os alunos poderiam alterar a velocidade do móvel por meio do indicador de nível no modelo. Nesse sentido, pedimos que explorassem a animação alterando os valores de velocidade. Em seguida, formulamos a seguinte pergunta: $\mathrm{O}$ que aconteceu quando vocês aumentaram a velocidade no móvel? O aluno A11 disse: Observei que o carro percorreu mais rápido a distância. Já $A 6$ disse: $O$ tempo no percurso alterou diminuindo o valor quando eu aumentei a velocidade. A7 também apontou que: $O$ indicador de aceleração não mexeu, ficou do mesmo jeito. A17 observou que: $O$ tempo diminui, quando a velocidade aumenta.

No momento em que estavam respondendo a questão, percebemos que alguns alunos utilizaram o tempo somente da ida como sendo o tempo do trajeto completo. Então, sentimos a necessidade de realizar a orientação: Observem que a questão está pedindo que você represente o tempo em um percurso de ida e volta. Nessa situação, qual o tempo representado na animação? $\mathrm{O}$ aluno $\mathrm{A} 3$ disse: Eu somei o tempo no percurso de ida e volta, então deu 28 segundos quando usei a velocidade de $50 \mathrm{~m} / \mathrm{s}$. Após nossa intervenção, todos os alunos conseguiram representar as repostas corretas: 28 segundos para uma distância percorrida pelo móvel de 1400 metros considerando a Velocidade Média Escalar de 50 metros por 
segundo. Percebemos, então, que algumas vezes os alunos não observam a interpretação da situação-problema, o que leva a erros que poderiam se evitados. Para Costa e Moreira (2001, p. 265-266),

A compreensão do enunciado depende de diversas variáveis dentre as quais destacamos a questão das representações: o enunciado é uma representação externa, uma descrição linguística que pode ou não ser acompanhada por representações pictórica (gráficos, figuras) de uma situação Física modelada. O sujeito deve, portando, ser capaz de dar significado à representação externa do problema, mas para isso ele necessita representá-la também internamente, ou seja, mentalmente, através de imagens, proposições.

Seguindo a atividade, os alunos partiram para a resolução da questão 5 , que abordou, novamente, o conceito de velocidade média escalar, bem como o de aceleração escalar. A partir da interação com a ferramenta nas questões anteriores, esperava-se que os alunos já possuíssem conhecimentos necessários para compreensão desse conceito. Dessa forma, solicitamos que fizessem as alterações propostas na questão e, em seguida, apresentassem suas respostas.

Assim, dos 19 alunos envolvidos, 16 apresentaram respostas corretas a essas questões. Nas suas resoluções, notamos a utilização da fórmula de velocidade média $[\mathrm{Vm}=\Delta \mathrm{S} / \mathrm{T}]$ e aceleração escalar $[\mathrm{A}=\mathrm{V} / \mathrm{T}]$. Já os outros 3 alunos ( $\mathrm{A} 5, \mathrm{~A} 7 \mathrm{e}$ A15) não responderam às questões. Ao ser questionado sobre o motivo de não ter respondido essa questão, o aluno $A 5$ retratou: Encontrei a resposta, mas não sei resolver, pois esquecei a fórmula, então não fiz. Tal resposta nos remete à hipótese levantada por Veit e Teodoro (2002). Segundo os autores, os alunos consideram a Física uma disciplina difícil, pois precisam memorizar fórmulas que, para eles, muitas vezes, não apresentam sentido. Assim, observando a dificuldade dos alunos em manipular as fórmulas, decidimos apresentá-las na área principal da animação da situação-problema proposta na atividade, pois o objetivo da atividade foi possibilitar aos alunos entender os conceitos de velocidade média e aceleração. Dessa forma, auxiliamos os estudantes a solucionar as questões utilizando primeiramente a animação, e seguida, com o uso das fórmulas. Apresentamos, na Figura 9, a resolução do aluno A3 nas questões 4, 5 e 6 .

Figura 9 - Resolução das questões do aluno A3

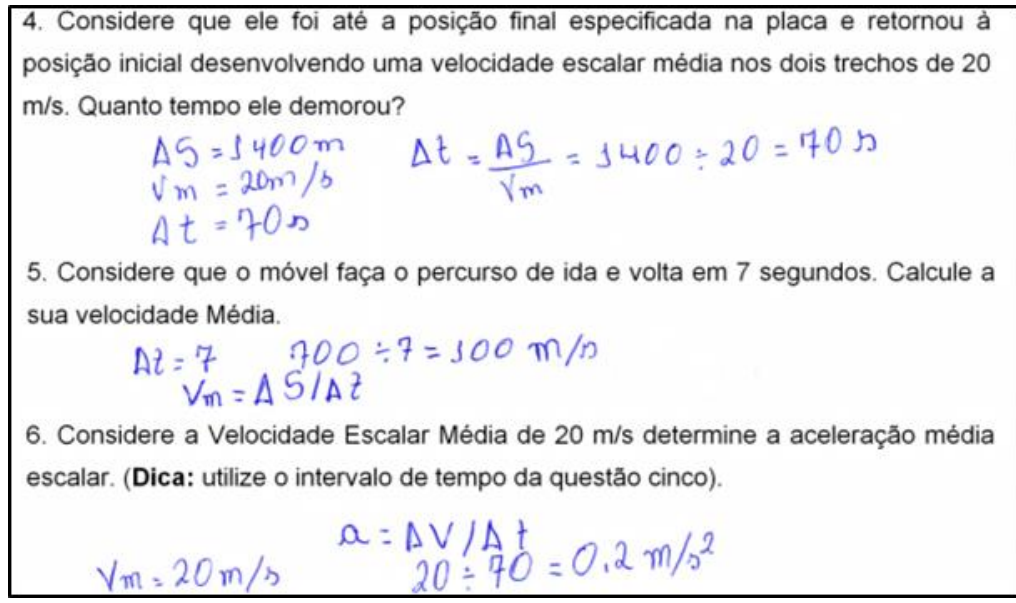

Fonte: Dados da pesquisa, 2014. 
Após, começamos a questionar os alunos para verificar as evidências de aprendizagem dos conceitos abordados. Assim, elaboramos a pergunta: A partir das questões respondidas da atividade, como vocês poderiam conceituar velocidade escalar média e aceleração escalar média? Apresentamos as três respostas levantadas sobre esses conceitos.

A3 - Professor! Entendo que a velocidade é quando dividimos a distância do móvel pelo tempo do trajeto.

A12 - Encontrei a aceleração quando dividimos a velocidade do móvel pelo tempo.

A16 - A velocidade e aceleração dependem do tempo do carro.

Apesar de poucos alunos se manifestarem nesse momento, evidenciou-se que o objetivo da atividade foi alcançado, pois ficou evidente a progressão de conhecimentos durante o desenvolvimento da atividade, bem como nas respostas apresentadas. Houve a troca de significados entre professor/pesquisador e os alunos. Nessa vertente, Moreira (2011) comenta que a aprendizagem significativa tem grande potencial de ser facilitada quando acontece intercâmbio entre os envolvidos, isto é, quando há negociação de significados, de modo que o professor atua como mediador dos processos de ensino e de aprendizagem.

Entendemos, ainda, que a opinião dos alunos acerca das atividades propostas é relevante para a avaliação da pesquisa desenvolvida, o que é apresentado no próximo item.

\section{Opiniões dos alunos quanto ao software Modellus usado na pesquisa}

Após desenvolver a prática, entregamos para os alunos um questionário para investigar a satisfação com relação à metodologia utilizada. Na primeira pergunta do questionário, indagamos os alunos participantes do estudo quanto à possível contribuição do uso do software Modellus nas resoluções dos problemas propostos. Assim, a primeira pergunta foi: Em sua opinião o software Modellus ajudou você na resolução dos problemas propostos? Por quê? Todos se posicionaram positivamente em relação à contribuição do programa para a solução dos problemas propostos nas atividades. Nesse sentido, destacamos a resposta do aluno A15: Sim, a visualização proporcionada pelo programa tornou mais fácil resolver os problemas.

Acreditamos, com base nas respostas dadas pelos alunos, que a investigação auxiliou no surgimento de duas das condições que Moreira (2011) aponta como necessárias para a ocorrência da aprendizagem significativa: o material de aprendizagem mostrou-se ser potencialmente significativo para os alunos e possibilitou que os alunos despertassem uma predisposição para aprender.

Nessa perspectiva, citamos a resposta do aluno A16 (Figura 10). Nela é possível notar que, para o aluno, a atividade facilitou a resolução de problemas, bem como lhe proporcionou o entendimento do conteúdo. 


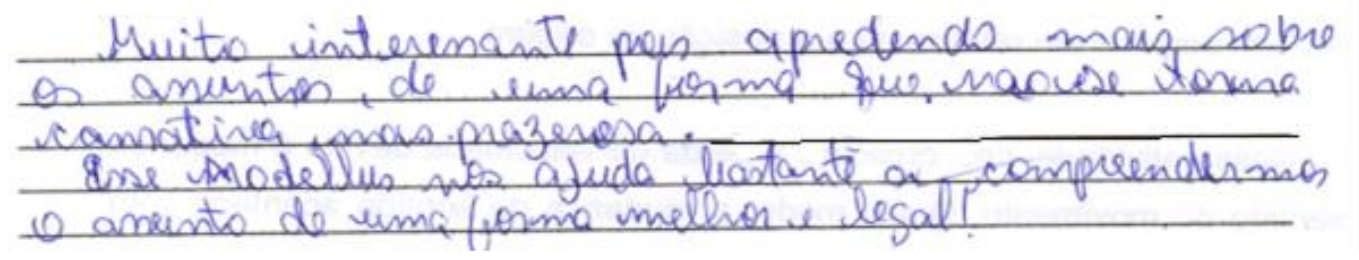

Fonte: Dados da pesquisa, 2014.

Na segunda questão, os alunos foram perguntados se achavam interessante o uso do computador nas aulas de Física. A pergunta foi: Você acredita que o uso do computador torna a aula mais interessante? Justifique? Em geral, os envolvidos afirmaram que sim e, como síntese das justificativas apresentadas, os estudantes alegaram que o uso do computador tornou a aula de Física mais interessante, divertida, prática e fácil. $\mathrm{O}$ aluno $\mathrm{A} 1 \mathrm{fez}$ a seguinte afirmação: Sim, o conteúdo tornou-se mais fácil de aprender, é legal usar o computador, ficou muito divertida a aula de Física. Já o aluno A7 declarou: Sim, porque a gente entende melhor o assunto e resolve os problemas com mais facilidade. Nessa mesma linha, A16 relatou: Sim, pois o computador, por ser uma tecnologia que todos gostam de usar, tornou a aula de Física interessante. Tais ponderações vão ao encontro das ideias de Araujo (2002), ao referir que há um interesse natural dos alunos em usar os computadores, e isso influencia de forma positiva para aprender o assunto abordado pelo professor.

A terceira questão tratou da facilidade de os alunos assimilarem as fórmulas que descrevem as situações-problemas utilizando a ferramenta tecnológica. Nesse viés, todos os alunos declararam que, por meio do programa, as fórmulas tornaram-se compreensivas. O aluno A10 respondeu essa pergunta da seguinte forma: Sim, pois o software Modellus ajudou a compreender as fórmulas visualizando o que ocorria na situação da animação e, isso facilitou meu entendimento do conteúdo. Já o aluno A7 disse: Sim, entendi as fórmulas na situação dos problemas com maior facilidade com o software. Diante do exposto, voltamo-nos às ideias de Juca (2006, p. 3):

\footnotetext{
A qualidade de um software educativo está relacionada com a capacidade que o computador, como mediador didático, tem de obter satisfação e êxito dos alunos na aprendizagem de um conteúdo ou habilidade. [...] seu desenvolvimento fundamentado em uma teoria de aprendizagem, a capacidade para que o aluno construa o conhecimento sobre determinado assunto, o poder de interação entre aluno e programa mediado pelo professor e a facilidade de atualização dos conteúdos.
}

Nesse sentido, consideramos que o software educativo Modellus desenvolveu habilidades nos alunos e, juntamente com a participação do professor, possibilitou, aos estudantes submetidos ao tratamento da pesquisa, a construção do conhecimento por meio da interação.

Considerando que o computador pode ser uma ferramenta facilitadora do ensino, e que as atividades propostas no software Modellus podem ser 
promotoras da aprendizagem, examinamos, na quarta questão, a opinião dos alunos em relação à metodologia de ensino e de aprendizagem empregada na pesquisa. Nesse sentido, os alunos relataram ter entendido melhor o conteúdo a partir do uso das animações. Alguns alunos enfatizaram que as atividades tornaram o aprendizado atraente e objetivo. O aluno A1 expressou-se nessa questão da seguinte maneira: Fica mais fácil entender, o professor faz perguntas da simulação e vemos no computador, como funciona na simulação, então fica fácil compreender quando vejo o que está acontecendo na animação. Já o aluno A9 afirmou: Fica mais fácil e interessante com animação do programa Modellus, responder as questões propostas. Tomado desse ângulo, Santos e Silva (2003, p. 4), embasados em Brown et al (1989), Lave et al (1991) e Schank et al $(1993,1994)$, descrevem que

\footnotetext{
Com as animações interativas, pode-se criar uma representação real ou ideacional de um fenômeno físico, apresentar aos alunos as características do fenômeno para a observação, além de serem sensíveis aos critérios individuais, onde o aprendiz pode agir na modificação das condições iniciais e observar as respostas, relacionar grandezas e outros atributos pertinentes ao fenômeno físico, estando o conhecimento amparado nos contextos nos quais os alunos aprendem [...] de tal forma que os subsunçores seriam modificados e ampliados para apreender o novo conhecimento.
}

Na quinta questão, os alunos relataram sua opinião sobre as aulas de Física no laboratório de informática. Todos se mostraram favoráveis e fizeram menção sobre a continuidade das aulas de Física nesse ambiente. O aluno A14 declarou: Eu achei muito boas as aulas no laboratório, pois é mais fácil aprender com um programa auxiliando. $\mathrm{O}$ aluno A15 disse: Muito bom e prazeroso, tirei minhas dúvidas quando surgiam e entendi um pouco mais a Física nesse lugar. Já o aluno A10 relatou: As aulas no laboratório foram boas, atraentes e bem tratadas, melhorei muito meu conhecimento no assunto. Por fim, destacamos o que o aluno A11 relatou: Espetacular, a aula no laboratório foi excelente para mim. Entendi bastante utilizando o computador, despertou meu empenho em estudar a Física.

$\mathrm{Na}$ sexta e última questão, sugerimos quatro opções para os alunos sinalizarem sua opinião, sendo que poderiam assinalar mais de uma opção. Assim, todos os alunos sinalizaram que o programa é uma ferramenta de fácil manuseio e facilita o aprendizado. Nesse sentido, avaliamos que as aulas de Física no laboratório de informática mostraram-se significativas para o ensino e a aprendizagem dos alunos envolvidos na pesquisa, e que o software Modellus possibilitou, por meio dos seus recursos, indícios do desenvolvimento da estrutura cognitiva dos alunos.

\section{Considerações Finais}

Ao concluir este estudo, vivenciamos atitudes e posturas que transcendem uma abordagem tradicional de ensino, o que contribuiu para que os alunos envolvidos na pesquisa tivessem uma nova concepção da disciplina da Física. Tal evidência se deu, principalmente, com relação a uma das características para a ocorrência da aprendizagem significativa, notada constantemente durante as atividades práticas desenvolvidas no laboratório de informática: a chamada a predisposição para aprender. 
Presenciamos a curiosidade dos alunos em aprender a Física, fato pouco observado durante as aulas expositivas tradicionais. Essa ponderação nos leva a refletir que, muitas vezes, os alunos carecem de um aprofundamento maior para haver, de fato, a compreensão do conteúdo trabalhado. Porém, a necessidade de cumprir o conteúdo programático da classe em sua totalidade faz com que alguns professores não tratem de alguns aspectos do programa com a devida minúcia, privilegiando a quantidade ao invés da qualidade do ensino. Nesse estudo, priorizamos a ação pedagógica, ao invés de quantidade de conteúdos, o que converge com Moreira (2011), ao afirmar que a facilitação da aprendizagem significativa depende muito mais de uma nova postura do professor, de uma nova diretriz, do que de novas metodologias, como as tecnologias de informação e comunicação.

Durante o desenvolvimento da atividade, agimos como mediadores dos processos de ensino e de aprendizagem, de modo a oportunizar que o aluno seja o protagonista da aula. Esse fato reforçou a necessidade de o docente repensar a metodologia no ensino, pois quando o aluno participa do processo de ensino, há um comprometimento próprio, que o faz querer aprender. Dessa forma, o desenvolvimento da aprendizagem acontece normalmente e naturalmente.

Os resultados desta pesquisa, que foi pautada nas animações computacionais, mostraram a relevância da implantação de um tratamento metodológico diferenciado no ensino na aprendizagem da Cinemática Escalar. Destacamos, ainda, que a metodologia proporcionou a participação dos estudantes na construção dos processos de ensino e de aprendizagem, haja vista o papel mediador que o professor assumiu em sala de aula, questionando os alunos sempre que vislumbrava respostas incorretas. As animações promoveram possibilidade de rodar, pausar, reiniciar e repensar conceitos. Cabe mencionar que a metodologia aplicada é viável quando se tem tempo para trabalhar com as turmas, já que as explorações das atividades são o ponto crucial da abordagem e necessitam de período maior para trabalhar o ensino, o que nós, professores de Física, habitualmente não costumamos ter ou disponibilizar.

Notamos, ainda, que, quando os alunos interagiam com o modelo proposto na investigação, os conhecimentos que já haviam sido apresentados em aulas expositivas foram modificados e ratificados. Em cada encontro, foram notados os esforços dos alunos para responder as questões, o que evidenciou o quanto os alunos querem aprender a Física, mas de modo diferente daquele dos métodos tradicionais.

Os resultados mostram que as atividades possibilitaram aos estudantes o desenvolvimento de subsunçores relacionados ao conteúdo abordado nas duas atividades práticas. Por meio dos modelos computacionais propostos para a investigação, de modo geral, alcançamos os objetivos elencados, pois, para solucionar as questões, os alunos buscaram neles as respostas que não estavam explicitas diretamente. Tais soluções, quase sempre, tinham relação à aplicação das equações; contudo, houve momentos em que as respostas foram apresentadas por meio de raciocínio dedutivo, bem como mediante textos descritivos. Por fim, dos pontos positivos notados no estudo, destacamos que ele:

- proporcionou a compreensão de conceitos relacionados à Cinemática escalar; 
- corroborou para o engajamento dos alunos nos processos de ensino e de aprendizagem;

- proporcionou o compartilhamento de significados entres os alunos-software Modellus e professor-alunos;

- possibilitou a familiarização dos alunos à linguagem característica da disciplina.

Ao final da pesquisa, propomos que futuras investigações realizadas nesta linha possam fazer uso dessa metodologia de ensino para aprofundar outros conceitos da Física. Além disso, sugere-se que seja utilizada em conteúdos de outras disciplinas, como Matemática e Química. 


\title{
Exploration of simulations as a way to stimulate the learning of concepts of Scalar Kinematics
}

\begin{abstract}
This document presents the article This Article shall aims at describing a practice developed with students of the 1st year of the Technical Course in Computer Integrated to High School - the Federal Institute of Education (CTIIEM), located in the municipality of Jari Orangery / Ap. Was inserted as the theoretical the concepts of meaningful learning, tabled by Ausubel (2003), and studies of Araujo (2002), Teodoro (2002), among others. The proposed methodology aimed to stimulate the students to actively learn, through the mediation of the teacher, the concepts of kinematics scalar. The technological tool was used Modellus software. Through this tool it was possible to explore computer simulations, providing opportunities for students to work with animations of virtual representations of the phenomena associated with the Physical Kinematics scalar The results showed that the methodology afforded interaction between students submitted to educational intervention as well as aroused predisposition to learn. Was possible to observe student satisfaction in being utilizing technological resources during his apprenticeship.
\end{abstract}

KEYWORDS: Meaningful learning. Software Modellus. Kinematics scalar. 


\section{REFERÊNCIAS}

APPOLINÁRIO, F.. Metodologia da ciência: filosofia e prática da pesquisa. 2oe ed. São Paulo. Cengage Learning, 2012.

AUSUBEL, D. P. Aquisição e retenção de conhecimento: uma perspectiva cognitiva. Lisboa: Plátano Edições Técnicas, 2003.

ARAUJO, I. Um estudo sobre o desempenho de alunos de Física usuários da ferramenta computacional Modellus na interpretação de gráficos em Cinemática. Dissertação de Mestrado. Instituto de Física, UFRGS, Porto Alegre; 2002.

ARAUJO, I.S.; VEIT, E. A.; MOREIRA, M. A. Atividades de modelagem computacional no auxílio à interpretação de gráficos de Cinemática. Revista Brasileira de Ensino de Física, São Paulo, vol. 26, n. 2, p. 179-184, 2004.

ARANTES, A. R.; MIRANDA, M. S.; STUDART, N. Objetos de Aprendizagem no ensino de Física: usando simulações do PheT. Física na Escola, v. 11, n. 1, 2010. Disponível em: <http://www.sbfisica.org.br/fne/Vol11/Num1/a08.pdf>. Acesso em: 12 fev. 2013.

BRASIL, Ministério da Educação, Secretaria de Educação Básica. Orientações Curriculares para o Ensino Médio. Brasília, vol. 2, 2006. Disponível em: $<$ http://portal.mec.gov.br/seb/arquivos/pdf/

CienciasNatureza.pdf>. Acesso em: 04 de abr. 2013.

CENNE, A. H. H.; TEIXEIRA, R. M. R. Retato de uma experiência didática envolvendo tecnologias computacionais no ensino de Física térmica. Encontro Estadual de Ensino de Física. Atas. Porto Alegre. IF-UFRGS. 2007. Disponível em < http://hdl.handle.net/10183/12959> Acesso em 08 Nov. 2013. 
EISNER, E. W. On ther differences between scientific and artistic approaches to qualitative research. Educational Research, 10(4): p.5-9, 1981.

FIOLHAIS, C.; TRINDADE, J. Física no computador como uma ferramenta no ensino e no aprendizado das ciências Físicas. Revista Brasileira de Ensino de Física. São Paulo, v. 25 n. 3 p. 259-272, set. 2003.

JUCA. S. C. S. A relevância dos softwares educativos na educação profissional. Ciências \& cognitivo v. 8. 2006. p. 22-28. Disponível em < http://www.cienciasecognicao.org/pdf/v08/cec_vol_8_m32689.pdf > Acesso em: 26 de Ago. 2014.

MENDES. E. S.; ALMEIDA, W. L. Uso do Software Modellus como ferramenta de apoio ao Ensino de Cinemática: um estudo de caso no Ifap. In: Congresso Norte Nordeste de pesquisa e Inovação, 2012, Palmas. Ciências, tecnologia e inovação: ações sustentáveis para o desenvolvimento regional. Disponível em: < http://propi.ifto.edu.br/ocs/index.php/connepi/vii/paper/view/1439/1083> Acesso em: 04 set. 2012.

MOREIRA, M. A.; MASINI, E. F. S. Aprendizagem significativa: a teoria da aprendizagem de David Ausubel. São Paulo: Centauro, 2002.

MOREIRA, M. A.; MASINI, E. F. S. Aprendizagem significativa: a teoria da aprendizagem de David Ausubel. 2 ed. São Paulo: Centauro, 2011.

MOREIRA, M. A. O que á afinal aprendizagem significativa. In:

Aprendizagem significativa: a teoria e textos complementares. 1 ํed. São Paulo: Livraria de Física, 2011.

MOREIRA, M. A. CABALLERO, M. C. RODRÍGUEZ, M. L. Aprendizagem significativa: um conceito subjacente. In. Encuentro Internacional sobre el Aprendizaje Significativo. Burgos, España,1997. p. 19-44.

NEIDE, I. G.; QUARTIERI, M. T. Recursos tecnológicos nos processos de ensino e de aprendizagem da Matemática e da Física. In: Aproximando a Matemática e a Física por meio de recursos tecnológicos: Ensino Médio . Dullius, M. M; Quartieri, M. T. (Org.) - Lajeado : Ed. da Univates, 2016. p. 9-14.

RAMOS, I. C. P. N. Construção de gráficos de Cinemática com o Software Modellus: Um estudo com Alunos do 11 ano de Escolaridade. Instituto de Educação da Universidade de Lisboa, Lisboa, 2011. Disponível em: < http://repositorio.ul.pt/handle/10451/5687> Acesso em: 03 set. 2013. 
SANTOS, J. N.; SILVA, R. T. Animação interativa como organizador prévio. In: XV Simpósio Nacional de Ensino de Física - Curitiba/PR - 2003. Disponível em: <http://www.fisica.ufpb.br/ romero/pdf/SNEF-15.pdf>. Acesso em: 23 jan. 2016.

TEIXEIRA, R. M. R.; VEIT, E. A. Introdução ao Modellus. 1999. Disponível em: $<$ https://www.lume.ufrgs.br/bitstream/handle/10183/135346/000285794.pdf?s equence=1>. Acesso em: 23 jan. 2016.

TEODORO, V. D. Modellus: Learning Physics with Mathematical Modelling. Tese Doutorado em Ciência da Educação. Universidade de Nova Lisboa, Faculdade de Ciência e Tecnologia, Nova Lisboa, 2002.

TEODORO, V. D. Modelação computacional em Ciências e Matemática. Revista Brasileira de Informática na Educação. Uniandes - Lidie, Colombia. v.10 .n.2,1997. p.171-182. Disponível em: <http://www.colombiaaprende.edu.co/html/mediateca/1607/articles112586_archivo.pdf> Acesso em: 02 set. 2013.

VEIT, E. A.; TEODORO, V. D. Modelagem no ensino/aprendizagem de Física e os novos parâmetros curriculares nacionais para o ensino médio. Revista Brasileira de Ensino de Física. V.24, n. 2, 2002, p. 87-96.

Recebido: 2014-12-17

Aprovado: 2017-02-07

DOI: $10.3895 /$ rbect.v10n2.2694

Como citar

MENDES, E. D. S.; REHFELDT, M. J. H.; NEIDE, I. G. Exploração de simulações como forma de estimular o aprendizado de conceitos da Cinemática Escalar. Revista Brasileira de Ensino de Ciência e Tecnologia, v. 10, n. 2, 2017. Disponível em: <https://revistas.utfpr.edu.br/rbect/article/view/2694>. Acesso em: xxx. Correspondência:

Elys Mendes da Silva

Av, Piracivaba, ㄲo 28 - Loteamento Bella Vista,

Bairro: Brasil Novo - Macapá - Amapá

Direito autoral: Este artigo está licenciado sob os termos da Licença Creative Commons-Atribuição 4.0 Internacional.

\section{(c) (i)}




\section{Apêndice A - Deslocamento em função da Distância Percorrida ${ }^{4}$}

\section{Objetivos}

Entender a diferença entre distância percorrida e deslocamento.

Entender o conceito de posição de uma partícula (corpo).

Compreender o conceito de movimento.

Para chegamos ao conceito de deslocamento e de distância percorrida, vamos realizar uma atividade prática utilizando o Software Modellus versão 4.01. Execute o arquivo que contém a atividade: Modelo 01 - Deslocamento em função da distância percorrido. mdl.

$\mathrm{Na}$ atividade apresentada na imagem, um atleta realiza uma corrida passando pela posição inicial de $100 \mathrm{~m}$ e, instantaneamente, inicia-se a cronometragem do tempo. Quando o atleta chega à posição final de $800 \mathrm{~m}$, para-se o cronometro. Em seguida, ele retorna para a posição de origem. Nessa atividade, desconsidere a perda de velocidade devido à mudança de sentido do movimento. Desse modo, a mudança de sentido acontece com velocidade absoluta constante.

Figura 14 - Modelo: Deslocamento em função da distância percorrida.mdl

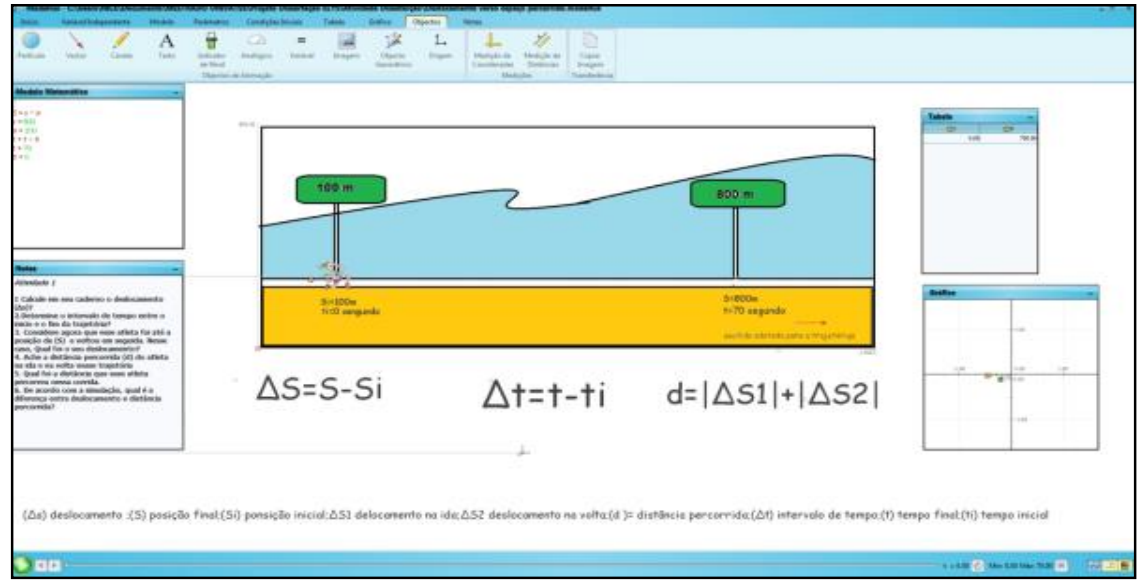

Fonte: Dos autores, a partir do Software Modellus versão 4.01

Păgina 488 Publicado como Produto Educacional no site do Mestrado Profissional em Ensino de Ciências Exatas no endereço: <http://www.univates.br/ppgece/media//pdf/2015/elys_da_silva_mendes.pdf>. 


\section{Atividade}

De acordo com a animação do Modelo 01 - Deslocamento em função da distância percorrido. mdl., responda as perguntas:

1. Calcule em seu caderno o deslocamento $(\Delta S)$.

2. Considere, agora, que o atleta foi até a posição de $(S)$ e voltou em seguida. Nesse caso, qual foi o seu deslocamento?

3. Determine o intervalo de tempo entre o início e o fim da trajetória.

4. Calcule a distância percorrida (d) do atleta na ida e na volta nessa trajetória.

5. De acordo com a animação, qual é a diferença entre deslocamento e distância percorrida? 


\section{Apêndice B- Velocidade Escalar Média e Aceleração Escalar Média ${ }^{5}$}

\section{Objetivos}

- Compreender que a velocidade média depende da distância percorrida por um móvel num intervalo de tempo.

- Entender o conceito de velocidade média no movimento retilíneo.

- Entender o conceito de aceleração escalar.

- Entender que a aceleração escalar depende da variação de velocidade, ou seja, a diferença entre a velocidade inicial e final de móveis, durante um intervalo de tempo.

Para chegamos ao conceito Velocidade Escalar Média, vamos realizar uma atividade prática utilizando o Software Modellus versão 4.01. Execute o arquivo que contém a atividade: Modelo 02 - Velocidade Escalar Média e Aceleração Escalar Média. mdl.

$\mathrm{Na}$ atividade apresentada na imagem, o móvel desloca-se numa trajetória retilínea. As unidades de aceleração, velocidade e distância são apresentadas na animação e estão de acordo com Sistema Internacional de Unidade (S.I).

Figura 15 - Modelo: Velocidade Escalar Média e Aceleração Escalar Média.mdl.

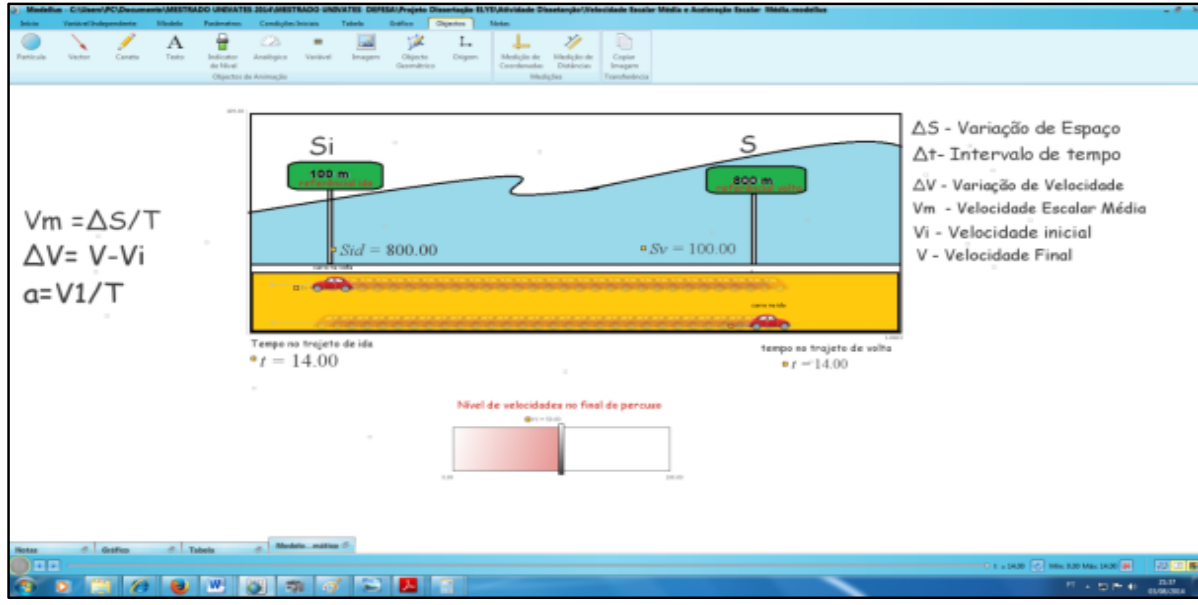

Fonte: Dos autores, a partir do Software Modellus versão 4.01

\section{Atividade}

1. Com base na animação do modelo 02 - Velocidade escalar média e aceleração escalar, responda:

a) Qual o deslocamento total do carro?

b) Quanto tempo ele levou na trajetória completa?

Păgina 505 Publicado como Produto Educacional no site do Mestrado Profissional em Ensino de Ciências Exatas no endereço: <http://www.univates.br/ppgece/media//pdf/2015/elys_da_silva_mendes.pdf>. 
c) Qual a Velocidade Escalar Média do trecho de ida e no trecho de volta?

d) Considerando a velocidade na volta, houve alteração com a mudança do sentido do movimento? Justifique.

2. Quanto ao sentido do movimento apresentado na animação, como se classifica o movimento na ida? Justifique.

3. Quanto ao sentido do movimento apresentado na animação, como se classifica o movimento na volta? Justifique.

4. Considere que ele foi até a posição final especificada na placa e retornou à posição inicial, desenvolvendo uma velocidade escalar média nos dois trechos de $20 \mathrm{~m} / \mathrm{s}$. Quanto tempo ele demorou?

5. Considere que o móvel faça o percurso de ida e volta em 7 segundos. Calcule a sua velocidade Média.

6. Considere a Velocidade Escalar Média de $20 \mathrm{~m} / \mathrm{s}$ e determine a aceleração média escalar. (Dica: utilize o intervalo de tempo da questão cinco).

\section{Apêndice C - Questionário de Satisfação}

1. Em sua opinião o Software Modellus ajudou você na resolução dos problemas propostos? Por quê?

2. Você acredita que o uso do computador torna a aula mais interessante? Justifique.

3. Você consegue assimilar com maior facilidade as fórmulas que descrevem as situações quando é utilizado o Software? Justifique sua resposta.

4. A Cinemática escalar fica mais fácil ou mais difícil de ser compreendida com a utilização de animação? Justifique.

5. O que você achou das aulas de Física no laboratório com o uso do Software Modellus? Justifique. 
6. Como você avalia o Software Modellus?

( ) Uma ferramenta de difícil manuseio.

( ) Uma ferramenta de fácil manuseio.

( ) Uma ferramenta que facilita o aprendizado.

( ) Uma ferramenta que não ajudou no meu aprendizado. 